\title{
Unusual Phenomenon of Forced Heat Exchange taking Place during Quenching Silver Probe in Cold Electrolyte
}

By Nikolai I. Kobasko

Abstract- It is shown in the paper that forced heat transfer exchange during quenching silver probes in cold electrolytes is explained by periodical replacement of short film boiling process by shock boiling. The frequency of such process is very high that increases cardinally heat transfer exchange. This phenomenon doesn't fit contemporary theory concerning nucleate boiling processes and needs further careful investigations. The reason for existing periodical process is a double boundary electrical layer where are acting increased electrical forces during quenching in electrolytes. In contrast of quenching steel, silver generates higher heat flux density during quenching; however full film boiling cannot be developed due to presence of high electrical forces in a double electrical layer caused by increased electrical conductivity of silver. The discovered phenomenon can be used in the practice in the future after its careful investigation to force heat transfer exchange by external electrical forces to eliminate any film boiling process during batch quenching.

Keywords: unusual phenomenon; film and shock boiling replacement; frequency; forced heat transfer exchange; future benefits.

GJSFR-A Classification: FOR Code: 020304

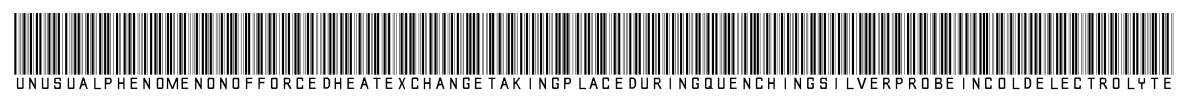

Strictly as per the compliance and regulations of:

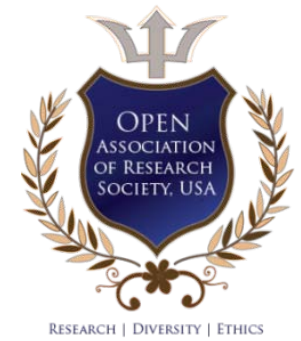

(c) 2020. Nikolai I. Kobasko. This is a research/review paper, distributed under the terms of the Creative Commons AttributionNoncommercial 3.0 Unported License http://creativecommons.org/licenses/by-nc/3.0/), permitting all non commercial use, distribution, and reproduction in any medium, provided the original work is properly cited. 


\title{
Unusual Phenomenon of Forced Heat Exchange taking Place during Quenching Silver Probe in Cold Electrolyte
}

\author{
Nikolai I. Kobasko
}

\begin{abstract}
It is shown in the paper that forced heat transfer exchange during quenching silver probes in cold electrolytes is explained by periodical replacement of short film boiling process by shock boiling. The frequency of such process is very high that increases cardinally heat transfer exchange. This phenomenon doesn't fit contemporary theory concerning nucleate boiling processes and needs further careful investigations. The reason for existing periodical process is a double boundary electrical layer where are acting increased electrical forces during quenching in electrolytes. In contrast of quenching steel, silver generates higher heat flux density during quenching; however full film boiling cannot be developed due to presence of high electrical forces in a double electrical layer caused by increased electrical conductivity of silver. The discovered phenomenon can be used in the practice in the future after its careful investigation to force heat transfer exchange by external electrical forces to eliminate any film boiling process during batch quenching.

Keywords: unusual phenomenon; film and shock boiling replacement; frequency; forced heat transfer exchange; future benefits.
\end{abstract}

\section{INTRODUCTION}

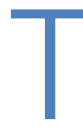
he author of the paper was dealing a long time with testing of different kinds of water salts solutions using spherical silver probe $20 \mathrm{~mm}$ in diameter. The silver probe was used to evaluate critical heat flux densities of water at different temperatures [1]. However, it was impossible to evaluate critical heat flux densities of water salt solution (electrolytes) using standard silver probe $20 \mathrm{~mm}$ in diameter because developed film boiling during quenching was completely absent. Nobody could explain such strange behavior of silver probe during its quenching in cold electrolytes. The matter is that thermal conductivity of silver at $100^{\circ} \mathrm{C}$ is equal to $392 \mathrm{~W} / \mathrm{mK}$ while thermal conductivity of steel is equal to $17.5 \mathrm{~W} / \mathrm{mK}$. It means that silver probe, according to law of Fourier, can generate during quenching 22 times larger heat flux density as compared with the steel. In this case developed film boiling must be presented. It was not present at all during testing of silver probe in cold electrolytes. Later scientists switched from silver standard probes to Inconel 600 probe $12.5 \mathrm{~mm}$ in diameter [2 - 5] and

Author: PhD, Fellow of ASM International, Intensive Technologies Ltd., Kyiv, Ukraine and IQ Technologies Inc., Ohio, United States.

e-mail:nkobasko@gmail.com started to use Liscic probe $50 \mathrm{~mm}$ in diameter $[6,7]$ for testing liquid media. A huge amount of experiments were carried out with water salt solutions using standard cylindrical probe $12.5 \mathrm{~mm}$ and Liscic probe $50 \mathrm{~mm}$ in diameter. Typical temperature cooling curves versus time for cylindrical probe $50 \mathrm{~mm}$ in diameter are illustrated in Fig. 1 [8]. As seen from Fig. 1, surface temperature of probe drops quickly almost to boiling point of a liquid that coincides very well with the accurate experiments of French [9]. After that surface temperature of probe maintains relatively a long time at the level of saturation temperature of a liquid until nucleate boiling is finished. Such behavior of surface temperature is called self - regulated thermal process $[10,11]$. There is an equation for its duration evaluation. According to authors [12], the heat transfer coefficient (HTC) decreases with decreasing core temperature of the probe during nucleate boiling process. These two main characteristics of the transient nucleate boiling process were taken into account when considering quenching silver probes in water salt solutions of the same concentration. Transient nucleate boiling analysis, observed during cooling steel probes and silver probes of different sizes, allows understanding the nature of forced heat transfer exchange during quenching silver probes in different kinds of electrolytes.

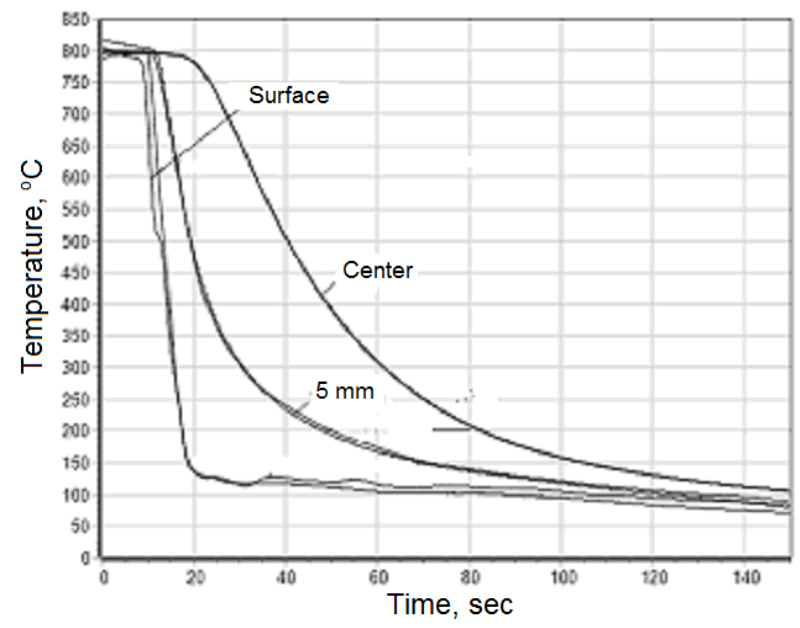

Fig. 1: Temperature curves versus time during quenching $50 \mathrm{~mm}$ in diameter cylindrical stainless probe in $14 \%$ water solution of $\mathrm{NaCl}$ at $23^{\circ} \mathrm{C}$ received by experiment [8] 
However, the problem concerning unusual behavior of silver probe during its quenching in electrolytes is not easy to solve. Currently, the Inconel 600 probe is used to get core cooling curves and core cooling rates during quenching of the probe. It has only one thermocouple located at its center. Authors [13] criticized the Inconel 600 probe and recommended using Liscic probe $50 \mathrm{~mm}$ in diameter with accurately instrumented through probe section three thermocouples. To solve the mentioned problem on unusual behavior of silver spherical probe during quenching in electrolytes, the author of the paper analyzes accurate experimental data obtained during testing electrolytes by silver spherical probe $20 \mathrm{~mm}$, steel cylindrical probe $12 \mathrm{~mm}$, and cylindrical probe 50 $\mathrm{mm}$ in diameter. Based on analyzing experimental data, one can came to conclusion that unusual behavior of silver probe during quenching in cold electrolytes is explained by periodical changing of film boiling by shock boiling that replace each other with the high frequency. Also, in the paper the contemporary theory on nucleate boiling process is considered to formulate ones again the boundary condition used for temperature field calculation during quenching when transient nucleate boiling takes place.

\section{il. Heat Transfer Coefficients Evaluation}

The standard probe for evaluating the cooling capacity of quenchants is discussed in [2]. Test methods based on ASTM Standards D6200-01, D648299, and D6649-00 for determining the cooling characteristics of quenchants are widely used in practice [2,3]. The chemical composition of Inconel 600 is: $72 \%$ nickel; $14-17 \%$ chromium; $6-10 \%$ iron; $0.15 \%$ carbon; $0.5 \%$ copper; and $0.5 \%$ silicon. The diameter of the probe is $12.5 \mathrm{~mm}$ and its length is $60 \mathrm{~mm}$. Probe details and its general assembly is provided in Ref.. [2].

Fig. 2 illustrates the spherical silver probe used for study unstable film boiling process [14]. The 20-mmdiameter spherical silver probe was prepared by casting the probe from the molten silver with a type $\mathrm{K}$ chromelalumel thermocouple inserted through a $1.5-\mathrm{mm}$ stainless steel sheath, with the thermocouple tip precisely located at the geometric center before casting. After casting, the silver surface was properly ground. The spherical shape of the probe was selected to ensure a uniform heat transfer.

To evaluate heat transfer coefficients and the heat flux density via solving inverse problem, the Liscic probe may be used $[6,7]$. This is the most accurate commercially available probe, obtaining the most accurate experimental data. Some experimental results are provided in [13].

The Liscic probe is an excellent tool for investigation of the self-regulated thermal process reported in Ref. [6, 7].

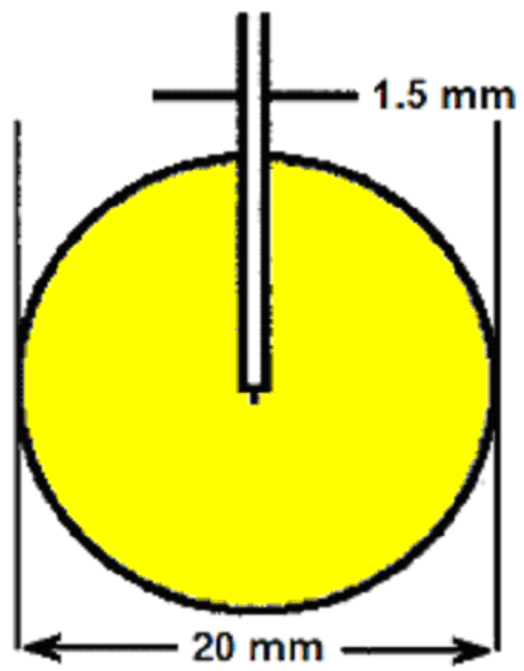

Fig. 2: The spherical silver probe used for testing of quenchants [14].

It was accepted by heat treating community that during quenching of silver probe in liquid media core temperature of the spherical probe always is equal to its surface temperature because thermal conductivity of silver is $400 \mathrm{~W} / \mathrm{mK}$ and effective heat transfer coefficient $(\mathrm{HTC})$ is not too high that all together always provides $\mathrm{Bi}$ $<0.2$. However, the condition $\mathrm{Bi}<0.2$ is not satisfied if consider real heat transfer coefficients (HTCs) instead of effective HTCs [12]. During quenching of silver probe essential temperature difference appears between core and surface temperatures. If so, the problem appears during solving inverse problem in evaluating correct values of HTCs. Probably, CFD modeling could help here. Currently, such computations are performed using CFD (computational fluid dynamics) methods mostly for plain convection, but unfortunately, it cannot be applied effectively yet to boiling processes, which are the main modes of heat transfer during quenching. That is why the regular thermal condition theory of Kondrat'ev was used for approximate evaluation of HTCs during boiling [14]. Also, accurate experimental data of author [15] were used which are shown in Fig. 3. Based on these data and thermal properties of silver and AISI 304 steel (see Table 1 - Tasble 3), HTCs were evaluated which are provided in Table 4. 


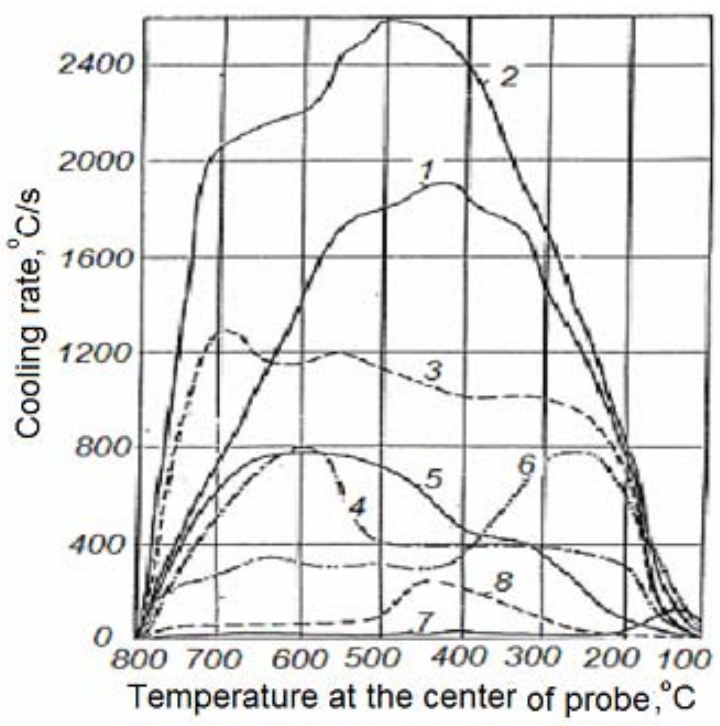

Fig. 3: Cooling rate curves at the center of spherical probe $20 \mathrm{~mm}$ diameter obtained during testing different quenchants [15]: 1, 2, 3 are water solutions of $\mathrm{NaCl}$ with concentration $5 \%, 15 \%, 20 \%$ at a temperature $20^{\circ} \mathrm{C} ; 4$ is $20 \%$ water solution $\mathrm{NaCl}$ at a temperature $60^{\circ} \mathrm{C}$; 5 is $50 \%$ water solution of $\mathrm{HNO}_{3}$ at a temperature $\left(96^{\circ} \mathrm{C}\right) ; 6,7$ is water at temperatures $20^{\circ} \mathrm{C}$ and $98^{\circ} \mathrm{C}$; 8 is industrial oil at a temperature $50^{\circ} \mathrm{C}$.

Table 1: Thermal conductivity of austenitre versus temperature

\begin{tabular}{|c|c|c|c|c|c|c|c|c|c|}
\hline T. ${ }^{\circ} \mathrm{C}$ & 100 & 200 & 300 & 400 & 500 & 600 & 700 & 800 & 900 \\
\hline$\lambda, \frac{W}{m K}$ & 17.5 & 18 & 19.6 & 21 & 23 & 24.8 & 26.3 & 27.8 & 29.3 \\
\hline $\bar{\lambda}, \frac{W}{m K}$ & 17.5 & 17.75 & 18.55 & 19.25 & 20.25 & 21.15 & 21.90 & 22.65 & 23.4 \\
\hline
\end{tabular}

Note $\bar{\lambda}$ is the mean value for the range between $100^{\circ} \mathrm{C}$ and the stated temperature.

Table 2: Thermal conductivity of copper and silver versus temperature

\begin{tabular}{|c|c|c|c|c|c|c|c|}
\hline Temperature. ${ }^{\circ} \mathbf{C}$ & 0 & 100 & 200 & 400 & 600 & 800 & 900 \\
\hline Copper $\lambda, \frac{W}{m K}$ & 393.1 & 384.9 & 380 & 365 & 353.5 & 340.8 & 333 \\
\hline Silver, $\lambda, \frac{W}{m K}$ & 410.5 & 392 & 372 & 362 & 374.5 & - & - \\
\hline
\end{tabular}

Table 3: Thermal diffusivity of austenitre versus temperature

\begin{tabular}{|c|c|c|c|c|c|c|c|c|c|}
\hline T. ${ }^{\circ} \mathrm{C}$ & 100 & 200 & 300 & 400 & 500 & 600 & 700 & 800 & 900 \\
\hline$a \cdot 10^{6}, \mathrm{~m}^{2} / \mathrm{s}$ & 4.55 & 4.63 & 4.70 & 4.95 & 5.34 & 5.65 & 5.83 & 6.19 & 6.55 \\
\hline $\bar{a} \cdot 10^{6}, \mathrm{~m}^{2} / \mathrm{s}$ & 4.55 & 4.59 & 4.625 & 4.75 & 4.95 & 5.10 & 5.19 & 5.37 & 5.55 \\
\hline
\end{tabular}

Note $\overline{\boldsymbol{a}}$ is the mean value for the range between $100^{\circ} \mathrm{C}$ and the stated temperature.

According to regular thermal conditions theory, cooling rate is directly proportional to Kondrat'ev number Kn (see Eq. (1)) [14]:

$$
K n=\frac{v K}{a\left(T-T_{s}\right)}
$$

Knowing Kondrat'ev number Kn, the generalized Biot number $\mathrm{Bi}_{\vee}$ was found using Eq. (2).

$$
K n=\frac{B i_{V}}{\left(B i_{V}{ }^{2}+1.437 B i_{V}+1\right)^{0.5}}
$$


Since the generalized Biot number is designed as

$$
B i_{V}=\frac{\alpha}{\lambda} K \frac{S}{V}
$$

$$
\alpha=\frac{\lambda B i_{V} V}{K S}
$$

the heat transfer coefficient was evaluated using Eq. (4)

Results of calculations are provided in Table 4.

\begin{tabular}{|c|c|c|c|c|c|}
\hline Material & $\begin{array}{l}\text { Probe, concentration } \\
\text { and temperature }\end{array}$ & $\mathrm{HTC}$ at $600^{\circ} \mathrm{C}$ & $\mathrm{HTC}$ at $500^{\circ} \mathrm{C}$ & $\begin{array}{l}\text { HTC at } \\
400^{\circ} \mathrm{C}\end{array}$ & $\begin{array}{l}\text { HTC at } \\
300^{\circ} \mathrm{C}\end{array}$ \\
\hline Silver & $\begin{array}{c}\text { Spherical probe } 20 \mathrm{~mm} \text { in } \\
\text { diameter cooled in } 5 \% \\
\text { water solution of } \mathrm{NaCl} \text { at } \\
20^{\circ} \mathrm{C}\end{array}$ & 23380 & 41170 & 59800 & 78500 \\
\hline Silver & $\begin{array}{c}\text { Spherical probe } 20 \mathrm{~mm} \text { in } \\
\text { diameter cooled in } 15 \% \\
\text { water solution of } \mathrm{NaCl} \text { at } \\
20^{\circ} \mathrm{C}\end{array}$ & 39380 & 66000 & 90650 & 100300 \\
\hline Silver & $\begin{array}{c}\text { Spherical probe } 20 \mathrm{~mm} \text { in } \\
\text { diameter cooled in } 20 \% \\
\text { water solution of } \mathrm{NaCl} \text { at } \\
20^{\circ} \mathrm{C}\end{array}$ & 18460 & 23000 & 27400 & 89400 \\
\hline Stainless steel & $\begin{array}{c}\text { Cylindrical probe } 50 \mathrm{~mm} \text { in } \\
\text { diameter cooled in } 1 \% \\
\text { water solution of UCON E } \\
\text { at } 23^{\circ} \mathrm{C}\end{array}$ & 4770 & 4590 & 2870 & 2600 \\
\hline Stainless steel & $\begin{array}{c}\text { Cylindrical probe } 50 \mathrm{~mm} \text { in } \\
\text { diameter cooled in } 14 \% \\
\text { water solution of } \mathrm{NaCl} \text { at } \\
23^{\circ} \mathrm{C}\end{array}$ & 3550 & 2930 & 2326 & 1440 \\
\hline Stainless steel & $\begin{array}{l}\text { Cylindrical probe } 12 \mathrm{~mm} \text { in } \\
\text { diameter cooled in } 6 \% \\
\text { water solution of } \mathrm{Na}_{2} \mathrm{CO}_{3} \text { at } \\
20^{\circ} \mathrm{C}\end{array}$ & 121430 & - & - & 8890 \\
\hline
\end{tabular}

Table 4: Heat transfer coefficients taking place during quenching of silver and steel probes in water salt solutions

As seen from Table 4, HTCs related to steel probes 12 and $50 \mathrm{~mm}$ in diameters are in good agreement with the existing theory of transient nucleate boiling processes taking place during quenching in electrolytes. Namely, the HTCs during nucleate boiling process follow the temperature gradients which were established during quenching of steel probes $12 \mathrm{~mm}$ and $50 \mathrm{~mm}$ (see Fig. 4). As known [16, 17], $\alpha_{n b} \propto q^{0.7}$. Since for smaller steel probe temperature gradient is larger (see Fig. 4), heat flux density released by it is larger too. It means that average HTC during nucleate boiling is larger for smaller probe. For steel probe 12 $\mathrm{mm}$ in diameter at a core temperature $600^{\circ} \mathrm{C}, \mathrm{HTC}$ is equal to $12180 \mathrm{~W} / \mathrm{m}^{2} \mathrm{~K}$ while for steel probe $50 \mathrm{~mm}$ in diameter HTC is equal to $3550 \mathrm{~W} /{ }^{2} \mathrm{~K}$. When core temperature in steel probe decreases, HTC decreases too (see Table 4). In contrast to obtained data, with decreasing core temperature of silver probe, the HTC increases almost three times. That can be true for developed film boiling process when it passes to transition boiling where HTC is significantly larger. However, HTCs are so large that they cannot belong to film boiling process. Such huge HTCs can be generated only by developed nucleate boiling process. In fact, it is something different that is not known yet to investigators. 


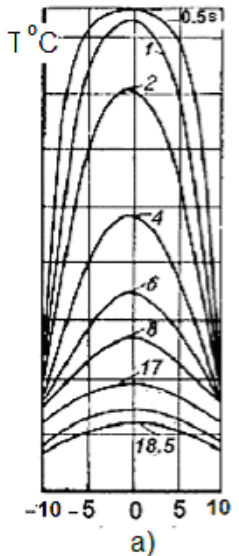

a)

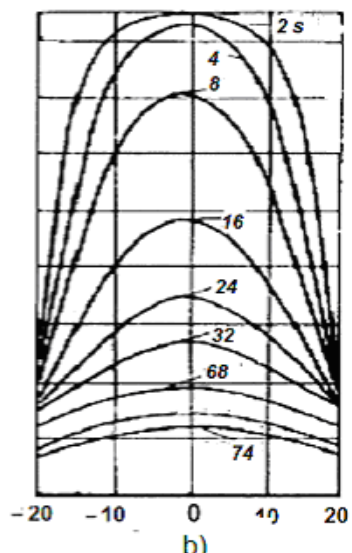

b)

Fig. 4: Temperature fields during quenching of cylindrical probes $20 \mathrm{~mm}$ (a) and $40 \mathrm{~mm}$ (b) in water salt solution of elevated concentration.

To find out what happens during quenching of silver probe in cold electrolytes and guess what in reality the unusual forced heat transfer exchange is, let's consider one more time the achievements of nucleate boiling processes theory.

\section{ili. Contemporary Theory Of Nucleate Boiling Processes}

As known, during quenching of metals they are heated and then immersed into a cold liquid, usually open quench tanks. At the time of immersion, boundary liquid boiling layer is formed. The boundary liquid layer is heated to the saturation temperature, and at the same time the part's surface is intensively cooled. Then the liquid at the boundary layer starts to boil and a certain heat flux density is reached that depends on the shape and sizes of the part and thermal conductivity of a material.

Depending on the initial heat flux density, film boiling can take place or can be absent.
It is important to find out the effect of vapor bubble behavior. As known, vapor bubble growth rate is determined as [16]:

$$
\bar{W}^{\prime \prime}=d_{0} f
$$

Experiments have not revealed the effect of heat flux density, which was changed by 4 or 5 times, on average value of $\bar{W}^{\prime \prime}$ [16].

The average vapor bubble growth rate $\bar{W}^{\prime \prime}$ is essentially affected by pressure

It is of great practical interest to know the effect of aqueous salt solution concentrations on inner characteristics of nucleate boiling process.

Results of experiments, dealing with boiling solutions of $\mathrm{NaCl}$ and $\mathrm{Na}_{2} \mathrm{CO}_{3}$ at normal pressure, are presented in Table 5.

Table 5: Effect of concentration on boiling inner characteristics [16 ]

\begin{tabular}{|c|c|c|c|}
\hline Substance & $d_{0}, \mathrm{~mm}$ & $f, 1 / \mathrm{s}$ & $W^{\prime \prime}, \mathrm{mm} / \mathrm{s}$ \\
\hline Water & 2.5 & 62 & 155 \\
\hline $25 \% \mathrm{NaCl}_{\text {solution }}$ & 2.4 & 64.5 & 155 \\
\hline $29 \% \mathrm{Na}_{2} \mathrm{CO}_{3}$ solution & 2.4 & 65 & 156 \\
\hline
\end{tabular}

As one can see from Table 5, for highconcentration solutions of $\mathrm{NaCl}$ and $\mathrm{Na}_{2} \mathrm{CO}_{3}$, their vapor bubble growth rates are the same and are equal to $W^{\prime \prime}$ of water. It means that concentration affects HTC during nucleate boiling process via Prandtl number Pr. It was shown that for different materials the vapor bubble growth rates are almost the same (see Table 6). 
Table 6: Effect of heated surface material upon bubble release diameter and release frequency of vapor bubblers [16].

\begin{tabular}{|c|c|c|c|c|c|c|}
\hline \multirow{2}{*}{ Material } & \multirow{2}{*}{$d_{o}, m m$} & \multirow{2}{*}{$f, 1 / \mathrm{s}$} & \multirow{2}{*}{$W^{\prime \prime}, \mathrm{mm} / \mathrm{s}$} & \multicolumn{3}{|c|}{ Average value } \\
\cline { 5 - 7 } & & & & $d_{o}, m m$ & $f, 1 / \mathrm{s}$ & $W^{\prime \prime}, \mathrm{mm} / \mathrm{s}$ \\
\hline Permanite & 2.5 & 61 & 153 & & & \\
\hline Brass & 2.3 & 67 & 157 & 2.5 & 62 & 155 \\
\hline Copper & 2.8 & 56 & 157 & & & \\
\hline
\end{tabular}

As follows from Table 6, inner characteristics of boiling process do not depend on sort of material. It means that for silver and steel inner characteristics of boiling process are similar.

Overheating in the boundary layer is higher when greater is heat flux density. When liquid overheating $\Delta T=T_{w}-T_{s}$ increases, the number of nucleating centers also increases. Number $n$ of nucleating centers increases by direct proportion to the cube of temperature difference:

$$
n \sim \Delta T^{3}
$$

At the same time, it is well-known that heat flux density at nucleate boiling in average is also proportional to the cube of temperature difference

$$
q \sim \Delta T^{3}
$$

It means that

$$
q_{0}=\frac{q}{n} \cong \text { const }
$$

When heat flux density $q$ increases, overheating $\Delta T=T_{w}-T_{a}$ of boundary layer also increases and new nucleating centers are activated. Average characteristics $d_{0}, f$ and $\bar{W}^{\prime \prime}$ are quite stable with respect to change of heat flux density. The most stable of them is average vapor bubble growth rate.

As known, $\alpha\left(\frac{W}{m^{2} K}\right)$ is considered during boiling as $\alpha=q / \Delta T[16,17]$.

The above mentioned HTC is used at the computation of temperature fields during steel quenching.

Tolubinsky proposed the generalized equation for calculation of the heat transfer coefficient at nucleate boiling process which has the following form [16]:

$$
\frac{\alpha}{\lambda} \sqrt{\frac{\sigma}{g\left(\rho^{\prime}-\rho^{\prime \prime}\right)}}=75\left(\frac{q}{r^{*} \rho^{\prime \prime} w^{\prime \prime}}\right)^{0.7}\left(\frac{a}{v}\right)^{0.2}
$$

Where $N u=\frac{\alpha}{\lambda} \sqrt{\frac{\sigma}{g\left(\rho^{\prime}-\rho^{\prime \prime}\right)}}$ is Nusselt number; the ratio $\sqrt{\frac{\sigma}{g\left(\rho^{\prime}-\rho^{\prime \prime}\right)}}$ is proportional to bubble release diameter.

From Eq. (9) follows that

$$
\alpha=75 \lambda\left[\frac{g\left(\rho^{\prime}-\rho^{\prime \prime}\right)}{\sigma}\right]^{0.5}\left(\frac{a}{v}\right)^{0.2}\left(\frac{1}{r^{*} \rho^{\prime \prime} w^{\prime \prime}}\right)^{0.7} \cdot q^{0.7}
$$

or

$$
\alpha=c q^{0.7}
$$

Where

$$
c=75 \lambda^{\prime}\left[\frac{g\left(\rho^{\prime}-\rho^{\prime \prime}\right)}{\sigma}\right]^{0.5} \cdot\left(\frac{a}{v}\right)^{0.2}\left(\frac{1}{r^{*} \rho^{\prime \prime} w^{\prime \prime}}\right)^{0.7}
$$

A well known handbook [17] provides equation (11) to be used for heat exchange design of technological processes:

$$
N u=0.082 K_{Z}^{0.33} \cdot K_{q}^{0.7} \cdot \operatorname{Pr}^{-0.45}
$$

Here

$$
\begin{aligned}
N u & =\frac{\alpha}{\lambda^{\prime}} \delta ; \delta=\left[\sigma / g\left(\rho^{\prime}-\rho^{\prime \prime}\right)\right]^{0.5} ; \\
K_{Z} & =\frac{c_{p} \rho^{\prime}\left(T_{w}-T_{s}\right) R_{c r}}{2 \delta \cdot r^{\bullet} \rho^{\prime \prime}} ; K_{q}=\frac{q \delta^{2}}{\rho^{\prime \prime} r^{\bullet} a^{\prime} l_{x}} ; \\
l_{x} & =\frac{c_{p} \sigma \rho^{\prime} T_{s}}{r^{\bullet} \rho^{\prime \prime}}
\end{aligned}
$$

From Eq. (11), one can get the same result

$$
\alpha=c q^{0.7}
$$

This fact is used for analyzing our calculated data. Thus, different authors came to conclusion that heat transfer during nucleate boiling depends on heat flux density value and is proportional to $q^{0.7}$. 


\section{iV. New Heat Exchange Phenomenon Taking Place during Quenching of Silver Probes}

According to statistical physics, free electrons in metal in heated area are under pressure $P$ which is calculated as [18]:

$$
P=n k T
$$

Here $\mathrm{n}$ is a number of electrons in one $\mathrm{sm}^{3}$ of metal; $\mathrm{k}$ is the Boltzmann constant which is equal to

$$
k=1.3806488(13) \times 10^{-23}\left[\mathrm{~K}^{-1}\right][18] \text {. }
$$

During immersion of heated to high temperature metallic probe into electrolyte, a double electrical layer is formed on the boundary liquid - metal which looks like it is shown in Fig. 5 [19-21]. It happens due to movement of electrons from heated area to cold area. Maximum electrical forcers take place when electrolyte is at an optimal concentration.

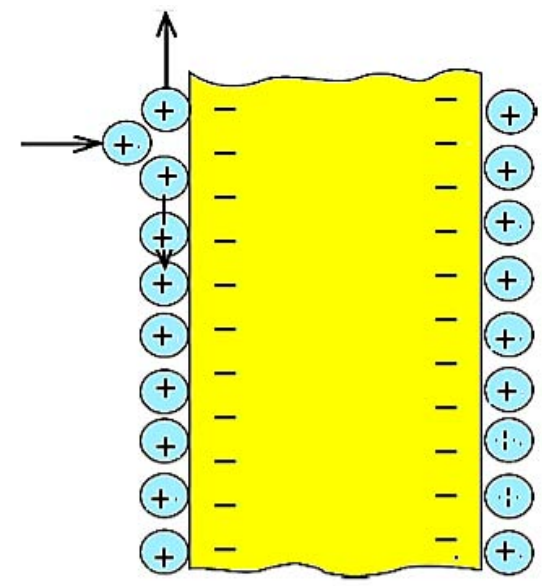

Fig. 5: A double electrical layer formed during immersion of heated probe into cold electrolyte [21].

A huge electrical force appears between surface of metal and electrolyte during quenching in electrolytes of optimal concentration. When quenching probe in cold electrolyte, cooling process can proceed by two ways as it is shown in Fig. $6[20,21]$.

During immersion of the heated probe into cold liquid, there are no bubbles on the metallic surface at all. At this time, cold liquid is heated to the boiling point of a liquid, and the surface temperature of the probe drops rapidly close to the saturation temperature $T_{s}$. During this extremely short period of time, heat transfer looks like a convection process. Any form and size of probe can be considered during this extremely short time as a semi - infinity plate which is intensively cooled. Cooling curves for different shapes and sizes are almost the same if film boiling is completely absent. Experiments of French support such behavior of cooling curves. When the liquid is overheated, shock boiling starts, and thousands of small bubbles appear, becoming larger with time. Simultaneously, a temperature gradient is established at the surface of the probe. From this moment of time, two different processes may be developed. The full film boiling is established when the initial heat flux density $q_{i n}$ is larger than the first critical heat flux density $q_{c r 1 \text {, i.e }} q_{\text {in }}>q_{c r 1}$. Nucleate boiling process occurs immediately after shock boiling when $q_{\text {in }<} q_{c r 1[22-23]}$.

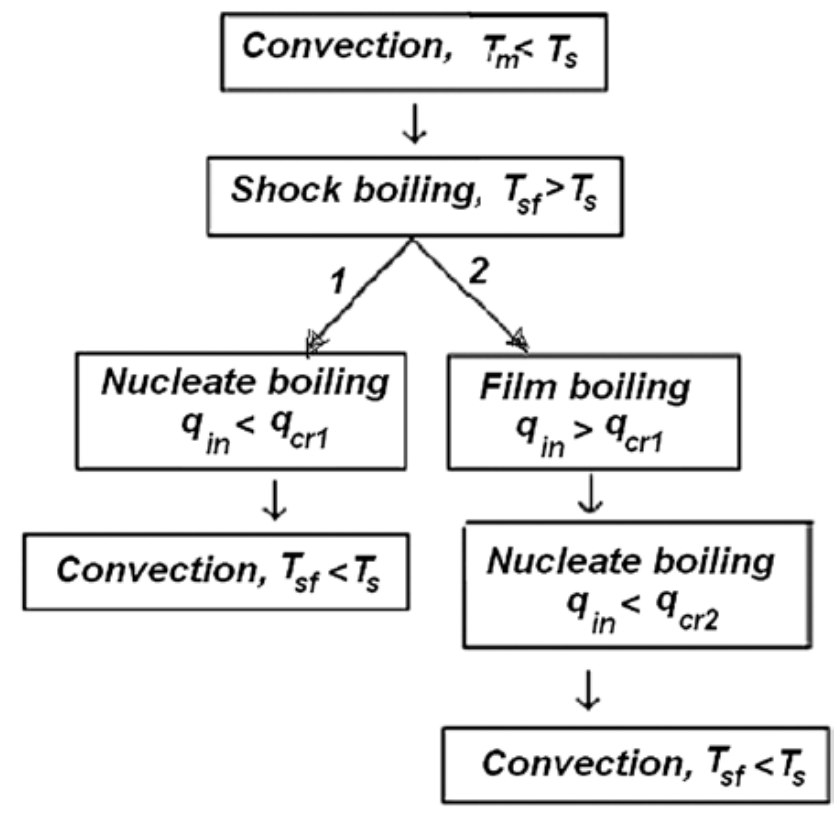

Fig. 6: Two possible boiling processes that may occur during quenching, depending on critical heat flux densities [22].

During steel quenching in cold electrolytes of optimal concentration film boiling is absent because initial heat flux density is below its critical value $\mathrm{q}_{\mathrm{cr} 1}$ [22]. However, during quenching of silver probes in electrolytes, initial heat flux density is so huge that it is always larger than the critical value $q_{c r 1}$. It is true because thermal conductivity of silver is almost 20 times larger as compared with steel. At room temperature thermal conductivity of silver is $400 \mathrm{~W} / \mathrm{mK}$ while for stainless steel it is only $14 \mathrm{~W} / \mathrm{mK}$. During quenching of silver probes in electrolytes electrical forces try to resist film boiling process establishment. Due to their presence, the high heat transfer coefficients (HTCs) can be generated by such a way. When film boiling appears, electrical forces move charged liquid layer to metal surface. The shock boiling starts immediately that creates the new film boiling layer which is a reason for periodical process. And such the periodical cooling process looks like:

film boiling $\rightarrow$ shock boiling. $\rightarrow$ film boiling $\rightarrow$ shock boiling $\rightarrow$ film boiling $\rightarrow$ shock boiling Oscillating with the high frequency, shock boiling process generates the high HTCs. 
This is a new physical process which can be very useful for practice because such physical process can be governed by external electrical forces to increase essentially HTCs. Especially, it is very important for direct quenching after forging of steel to receive super strengthened materials of high ductility and high wear resistance.

There are three vital ways of affecting and governing boiling processes during quenching to improve radically technological processes aiming service life increase of steel parts and environment improvement. They are:

- Adjusting pressure to delay or accelerate martensitic transformation

- Creating surface insulating layers to drop initial heat flux density below its critical value to prevent completely any film boiling process during quenching of steel parts

- Governing boiling process by external electrical forces to increase HTCs

\section{Discussion}

From consideration the existing theory of nucleate boiling processes follows that heat transfer coefficient during nucleate boiling is calculated as shown by Eq. (10 a) and Eq. (11a). Both equations can be rewritten as

$$
\begin{gathered}
\alpha=c q^{0.7} ; q=\alpha\left(T-T_{s}\right) ; \\
\alpha=c \alpha^{0.7}\left(T-T_{s}\right)^{0.7} ; \\
\alpha^{0.3}=c\left(T-T_{s}\right)^{0.7} ;
\end{gathered}
$$

or

$$
\alpha=c^{3.33}(T-T)^{2.33} .
$$

Substituting obtained result (13) into third kind of a boundary condition, we obtain:

$$
\left[\frac{\partial T}{\partial r}+\frac{\beta^{10 / 3}}{\lambda}\left(T-T_{s}\right)^{10 / 3}\right]_{r=R}=0
$$

Based on the obtained boundary condition (14), an analytical solution was received [12] for quenching steel parts in liquid media that resulted in a well known characteristic of transient nucleate boiling process which is written now as:

$$
\tau_{n b}=\bar{\Omega} k_{F} \frac{D^{2}}{a}
$$

This final result was many times verified by accurate experiments which coincided very well with the calculated data. It means that above considered theory of boiling processes is suitable for steel parts quenching since it was many timers supported by experiments.

However, the theory cannot support the discussed above the unusual phenomenon on oscillating and periodical changes of shock and film boiling processes. In this specific case, the boundary condition should include the effect of electrical forces which were not considered yet by physicians. Further investigating the unusual heat exchange process, one can expect essential benefits for heat treating industry and other new technologies development.

\section{Vi. Conclusions}

1. A new forced heat transfer phenomenon is considered in this paper. Its essence consists in periodical replacement of film boiling by shock boiling that considerably increases heat exchange process during quenching of metal components in water salt solutions of optimal concentration.

2. The discovered new phenomenon can be governed by external electrical forces that in the nearest future will compete with the powerful pumps and propellers focused on eliminating film boiling processes.

\section{Nomenclature}

\begin{tabular}{ll}
$B i$ & Biot number \\
$B i_{V}$ & Generalized Biot number \\
$K n$ & Kondrat'ev number \\
$N u$ & Nusselt number \\
$\psi$ & Non smoothness of temperature field \\
$\alpha$ & Heat transfer coefficient \\
$\alpha_{n b}$ & Heat transfer coefficient during NB \\
$a$ & Thermal diffusivity of solid material \\
$a^{\prime}$ & Thermal diffusivity of liquid \\
$C_{p}$ & Specific heat capacity \\
$\Omega$ & Function of convective Biot number \\
$\lambda$ & Thermal conductivity of a solid material \\
$\lambda^{\prime}$ & Thermal conductivity of liquid \\
$\rho^{\prime}$ & Density of liquid \\
$\rho^{\prime \prime}$ & Vapor density \\
$R_{c r}$ & Critical radius of growing vapor bubble \\
$r^{\bullet}$ & Latent heat of evaporation i \\
$v$ & Cooling rate during quenching \\
$\sigma$ & Surface tension \\
$D$ & Diameter or thickness \\
$R$ & Radius \\
$\tau$ & Time in seconds \\
\hline
\end{tabular}


$K \quad$ Kondrat'ev size factor in $\mathrm{m}^{2}$

$k_{F} \quad$ Form coefficient

$q \quad$ Heat flux density

$q_{\text {in }} \quad$ Initial heat flux density $\mathrm{W} / \mathrm{m}^{2}$

$T_{w} \quad$ Wall temperature in ${ }^{\circ} \mathrm{C}$

$\bar{T}_{w} \quad$ Average wall temperature in ${ }^{\circ} \mathrm{C}$

$\bar{T}_{V} \quad$ Average volume temperature in ${ }^{\circ} \mathrm{C}$

$g \quad$ Gravity acceleration

$W^{\prime \prime} \quad$ Vapor bubble growth rate

$v \quad$ Kinematic viscosity

\section{References Références Referencias}

1. Kobasko, N. I., Moskalenko, A.A., Totten, G.E., and Webster, G.M., Experimental etermination of the First and Second Critical Heat Flux Densities and Quench Process Characterization, Journal of Materials Engineering and Performance, Vol. 6, No. 1, 1997, pp. 93-101.

2. Totten, G. E., Bates, C.E., and Clinton, M.A., Handbook of Quenchants and Quenching Technology, ASM International, Materials Park, $\mathrm{OH}$, 1993, pp. 69-128.

3. ASTM Standard D6200-97: Standard Test Method for Determination of Cooling Characteristics of Quench Oils by Cooling Curve Analysis, Annual Book of ASTM Standards, ASTM International, West Conshohocken, PA, 2001.

4. ASTM Standard D6482-99: Standard Test Method for Determination of Cooling Characteristics of Aqueous Polymer Quenchants with Agitation (Tensi Method), Annual Book of ASTM Standards, ASTM International, West Conshohocken, PA, 2000.

5. ASTM Standard D6549-00: Standard Test Method for Determination of Cooling Characteristics of Quenchants by Cooling Curve Analysis with Agitation (Drayton Unit), Annual Book of ASTM Standards, ASTM International, West Conshohocken, PA, 2000.

6. Liscic, B., Tensi, H. M., Luty, W. (Eds.), Theory and Technology of Quenching. Berlin: Springer, 1992, 484. doi: 10.1007/978-3-662-01596-4

7. Liscic, B., Measurement and Recording of Quenching Intensity in Workshop Conditions Based on Temperature Gradients. Materials Performance and Characterization, 5 (1), 2016, 209-226. doi: 10.1520/ mpc20160007.

8. Kobasko, N.I., Moskalenko,A.A., Logvinenko, P.N, Dobryvechir, V.V., New direction in liquid quenching media development, Теплофізика та теплоенергетика, 2019, т. 41, №3 pp. 33 - 40.
9. French H.J., The Quenching of Steels. American Society for Steel Treating, Cleveland, Ohio, USA, 1930.

10. Kobasko NI. Steel Quenching in Liquid Media under Pressure. Naukova Dumka, Kyiv, 1980.

11. Kobasko NI., Self - Regulated Thermal Processes During Quenching of Steels in Liquid Media. International Journal of Microstructure and Materials Properties. 2005; 1(1):110-125.

12. Kobasko N.I., Mechanism of film elimination when intensively quenching steel parts in water polymer solutions of low concentration, Global Journal of Science Frontier Research - A: Physics and Space Science, Vol. 20, Issue 7, 2020, pp. $39-56$.

13. Kobasko $\mathrm{N}$ and Liscic B., Liscic/Petrofer probe to investigate real industrial hardening processes and some fundamentals during quenching of steel parts in liquid media, EUREKA: Physics and Engineering, Number 6, 2017, pp. 48 - 56. DOI: 10.21303/24614262.2017.00495

14. Kondrat'ev GM, Teplovye Izmereniya. (Thermal Measurements). Mashgiz, Moscow, 1957.

15. Petrash L.V., Quenchants, Mashgiz, Moscow Leningrad, 1959, $112 \mathrm{p}$.

16. Tolubinsky, V. I., Heat Transfer at Boiling, Naukova Dumka, Kyiv, 1980, 316 p.

17. "Heat Exchanger Design Handbook I. Heat Exchanger Theory. Contributors: D. Brian Spalding, J. Taborek, (1983), Hemisphere Publishing Corporation, New York, USA, 561 p.

18. Nozdrev B.F, Senkevich AA. Course of Statistical Physics. Vysshaya Shkola, Moscow, 1969.

19. Frenkel Ya.I. Kinetic Theory of Liquids. Nauka, Leningrad, 1975.

20. Fedorov V.I., Kovalenko G.V., Kostanchuk D.M., Boiling of fluid on a metal surface. Journal of Engineering Physics. 1977; 32(1):10-14. DOI: 10.1007/bf00860120.

21. Kobasko N.I., Effect of free electrons in steel on its quenching process in water and water salt solutions. EUREKA: Physics and Engineering, Number 1, 2018, pp. 39-46. DOI: 10.21303/24614262.2018.00529

22. Kobasko N.I., Aronov M.A., Powell J.A., Totten G.E., Intensive Quenching Systems: Engineering and Design, ASTM International, USA, 2010, 234 p.

23. Kobasko, N.I., Transient nucleate boiling process as a basis for designing of high efficiency innovative technologies, International Journal of Physics and Applications, Vol. 2, Issue 1, 2020, pp. 6-16.

$$
\text { and }
$$

